DOI: https://doi.org/10.24297/jal.v12.8985

\title{
A Study on Mandarin Proficiency and Multidimensional Poverty in Ethnic Areas
}

\author{
Lucong Wang ${ }^{1}$ \\ ${ }^{1}$ School of Economics, Central University of Finance and Economics, Beijing, China \\ Lucong Wang, School of Economics, Central University of Finance and Economics, Beijing, China. E-mail: \\ wanglucongc@163.com
}

\begin{abstract}
To study the role of language in anti-poverty, based on the theory of multidimensional poverty and the economic value of language, this paper analyzes the correlation between Mandarin proficiency and multidimensional poverty in ethnic minority areas by using CFPS data from 2010 to 2018. The regression results show that the improvement of Mandarin proficiency is beneficial to solve multidimensional poverty problems. The endogenetic analysis and robustness test are carried out, and the conclusion is consistent with the baseline regression. Further, the influence of language ability on different samples is analyzed. The study shows that Mandarin proficiency has a greater influence on male, 18-28 and 29-50 years old, high poverty groups and nonagricultural workers.
\end{abstract}

Keywords: Mandarin Proficiency, Multidimensional Poverty, Ethnic Minority Areas

\section{Introduction}

From the perspective of economics, language is a kind of human capital. Language acquisition and use are beneficial to improve the professional skills and literacy of laborers, increase the income level and employment level on the micro level, and it is beneficial to improve the language ability and literacy of the national people, and improve the level of economic development on the macro level. The externality of language is conducive to reducing transaction costs, enhancing communication intention, forming "learning effect" and "spillover effect" of knowledge, promoting individual innovation and entrepreneurship and regional economic growth, and the improvement of language ability is also beneficial to reduce the negative externality of poverty. As a kind of public goods, which means that the promotion of national lingua franca and the supply of language services in China need to formulate correct language policies and plans. As a meta-system, language regulates people's use of language, which is conducive to reducing transaction costs, improving communication efficiency and promoting the development of international trade and other economic activities. From the national level, the essence of language as a communication tool and cultural carrier is of great practical significance in strengthening national unity and cohesion, ensuring social harmony and stability in the border areas. Therefore, the acquisition and use of languages have multiple economic effects and practical significance, especially the use of lingua franca, which has greater utility in ethnic areas. At the same time, Amartya Sen's capability poverty theory holds that poverty is not only the poverty of income dimension, but also the lack of feasible ability in education, resource use and development opportunities, which is caused by the lack of ability. It is easy to ignore the essence of poverty by measuring poverty only by income level, which leads to the instability of getting rid of poverty in economic dimension due to the lack of education, health, resource use and so on. Therefore, we take language poverty alleviation as the starting point to analyze the relationship between Mandarin proficiency and multidimensional poverty. 


\section{Literature Review}

With the development of education economics and human capital theory, Jacob Marchak (1965), a pioneer of the West and professor of economics at UCLA, put forward the concept of linguistic economics, which explains the essence of language economics: value and utility, cost and income, which opens the prelude of the study of world linguistic economics. As a human capital, language acquisition and use have an impact on income and employment. Therefore, most scholars focus on the relationship between language and income to study language of poverty alleviation. Carliner (1981) takes Quebec province as an example, and finds that people who speak French or English have a greater economic return than those who can't speak both languages, while English speakers have a greater financial return than French speakers. Outside Quebec, the wage level of English speaking people alone is significantly higher than that of those who can neither speak English nor speak French. Walter McManus \& William Gould \& Finis Welch (1983) explored the role of English proficiency in the integration of Hispanic men into the U.S. labor market, pointing out that Hispanic men's differences in English skills largely result in their wage differences. Evelina Tainer (1988) believes that English proficiency has a significant positive impact on the income of all ethnic groups, especially for foreign born Hispanics and Asians, whose income is most affected by English proficiency. Barry R. Chiswick \& Harry Anthony Patrinos \& Michael E. Hurst (2000) analyzed the impact of Spanish and indigenous language use on labor force participation and income in Bolivia, and pointed out that the labor income of Spanish proficient workers is about $25 \%$ higher than that of native language speaking workers. Michael A. shields \& Stephen Wheatley price (2002) not only studies the assimilation experience of British minority immigrants, but also studies the key factors of their English fluency in career success. He believes that the English fluency of British minority immigrants is significantly related to the average hourly wage. Alisher Aldashev \& Johannes Gernandt \& Stephan L. Thomsen (2008) studies show that the level of German speaking of foreigners in Germany will have an impact on their economic income. As for foreign students, the participation rate and employment rate of foreign students with High German level are also high, and the Low German level will also affect their career choice. Daniela Casale \& Dorrit posel (2011) discuss the relationship between English proficiency and income in South Africa. It is believed that Africans with better English skills have great income, not only can they improve their economic income, but also improve their social status. The research of Mehtabul Azam \& Aimee Chin \& Nishith Prakash (2013) found that compared with those who can't speak English, the hourly wages of the workers who are fluent in English and those who speak a little English are $34 \%$ and $13 \%$ higher respectively; the wage increase for the English speaking workers is equivalent to the hourly wage of the high school educated workers, and the hourly wage of the college degree workers. $\mathrm{Di}$ Paolo Antonio \& Tansel Aysit (2015) analyzed the economic value of foreign languages in Turkey based on the data of about 6000 adult male wage earners in 2007, and found that proficiency in English, Russian, French and German will bring positive income return, and increase with the improvement of ability level; however, in contrast, knowledge of Arabic will not generate income premium. Christian Dustmann \& Francesca Fabbri (2003) conducted an empirical study on the influencing factors of non-white immigrants' language acquisition and the correlation between their English skills and their income and employment probability, and found that the English level of non-white immigrants was positively correlated with their employment probability and labor income.

As a common language in China, the acquisition of Mandarin is also a way to increase human capital, so it also has an impact on individual income and employment. Chen Yuanyuan (2016) used three sets of comprehensive data from China Family Panel Studies (CFPS), China Labor-force dynamic survey (CLDS) and Chinese General Social Survey (CGSS) to test the impact of Mandarin proficiency on labor income. The study found that Mandarin and single item (listening and speaking) had a significant impact on labor income, and had a significant positive impact on the income of waiters and rural workers. Zhao Ying (2016) divided the workers into urban workers and rural migrant workers, with the help of Chinese General Social Survey data in 2010, and used to investigate 
the impact of Mandarin on their income. The results show that the impact of language ability on the income of workers in China's labor market is between $11.62 \%$ and $15.6 \%$, and the impact of Mandarin listening ability and Mandarin expression ability on the occupational income of workers. Jinjiang, Yin Feifei and Lian Jie (2017) based on the 2010 China (Guangzhou) family dynamic tracking survey data, using probit model to investigate the relationship between Mandarin proficiency and employment of Guangdong residents, the research shows that Mandarin proficiency can significantly improve men's employment situation, which is conducive to workers engaged in mining, manufacturing and construction industry, trade services and communications. From the perspective of Mandarin proficiency and income and employment of migrant workers, Qin Guangqiang (2014) analyzed the impact of Mandarin proficiency of migrant workers in Beijing on their income. The study found that migrant workers who are proficient in Mandarin can get $21 \%-40 \%$ of their monthly income higher than those who are not proficient in Mandarin, and those who are proficient in mandarin have better performance in job training, vocational skills, self-worth, job adaptation, etc. Jiang Shan (2017) and Xia Li (2009) found that Mandarin has a significant positive impact on non-agricultural income, and the hourly wage of migrant workers with Mandarin standard is $15.73 \%$ higher. More than $70 \%$ of migrant workers think that "if they speak Mandarin well, they can find a good job". Wang Hailan (2019) take Bomi County, Nyingchi City, Tibet Autonomous Region as the research object, and focus on the relationship between Mandarin proficiency and income from three aspects: willingness to learn Mandarin, motivation to learn Mandarin and Mandarin learning. The research shows that the improvement of workers' Mandarin listening level, speaking ability and writing ability can significantly improve individual labor income. Tang Manping and Li Houjian (2019) used the economic and social survey data of Western Ethnic Areas in 2012. The influence of Mandarin proficiency on the net income and Engel coefficient of farmers was investigated from the perspective of income and consumption. The influence showed that the ability of spoken Chinese communication and Chinese reading and writing can play a role in poverty reduction of farmers in southwest ethnic areas, and its mechanism of action of poverty reduction is mandarin skills to help farmers increase the probability of local nonfarm workers, increase the channels of information search, so as to promote poverty reduction effect. Bian Chenglin et al. (2019) divided Mandarin proficiency into four levels of "can't, slightly understand, general and familiar", and conducted a full sample survey on Mandarin proficiency, income and employment of residents within $0-3 \mathrm{~km}$ of Dongxing on the Sino Vietnamese border to investigate the impact of language ability on poverty alleviation, the study found that the average annual income of the people who can't speak Mandarin is 17034 yuan less than those who master Mandarin, which is nearly 1500 yuan lower than the average monthly income. Xie Zhiju and Li Qiang (2020) analyzed the ability, demand and income of Mandarin in villages of 12 counties in G Province, and found that Mandarin mainly affects the income of poor households. The income of those who can speak Mandarin is 6965 yuan higher than those who can't speak Mandarin, which is $32.8 \%$. At the same time, the improvement of Mandarin proficiency increases the poverty alleviation rate by $20 \%$.

To sum up, as a human capital attribute, the improvement of lingua franca is conducive to the improvement of individual income and employment level of workers. However, most of the above literatures only studies language and anti-poverty from the single perspective of language, income and employment, while the multidimensional research of language and health, education, living standard and employment is less. Therefore, this paper selects 15 indicators from the five dimensions of economy, health, education, living standards and employment to build a multidimensional poverty index, and analyzes the relationship between Mandarin proficiency and multidimensional poverty. 


\section{Mandarin Proficiency and Multidimensional Poverty Analysis}

\subsection{Calculation of Multidimensional Poverty Index}

\subsubsection{Data Resource}

The data used in this paper are mainly from the national sample of the China Family Panel Studies (CFPS) from 2010 to 2018, which is a biennial follow-up survey conducted by the Chinese Center for Social Science Survey at Peking University. The survey aims to comprehensively reflect the social changes and economic development in China by collecting nationally representative information on villages, families and family members. According to the research of this paper, rural residents in eight ethnic provinces of China are selected as the research object to analyze their multidimensional poverty in the dimensions of economy, education, health, living standard, work.

\subsubsection{Indicators Selection}

In order to comprehensively present the situation of multidimensional poverty in ethnic areas, we analyze the situation of multidimensional poverty in ethnic areas from five dimensions: economy, education, health condition, work condition and living standard. The economic dimension is replaced by per capita disposable income, while the education dimension is represented by years of education and dropout rate. The health condition is measured from three aspects: self-rated physical health, chronic disease and mental health. Work condition is measured from five aspects: employment, work formality, satisfaction with work environment, satisfaction with job promotion and information resources. Living standard from medical insurance, cooking water, cooking fuel, culture, education and entertainment expenditure ratio of 4 aspects to measure.

Table 1 Multidimensional Poverty Indicators and Weight Description

\begin{tabular}{|c|c|c|}
\hline Dimension & Indicators & Description \\
\hline $\begin{array}{l}\text { Economic level } \\
(1 / 5)\end{array}$ & $\begin{array}{l}\text { Disposable income per } \\
\text { capita }(1 / 5)\end{array}$ & $\begin{array}{l}40 \% \text { of income per capita, If it is greater than this, it is } 0 \text {, } \\
\text { otherwise it is } 1 .\end{array}$ \\
\hline \multirow[t]{2}{*}{$\begin{array}{l}\text { Education } \\
\qquad(1 / 5)\end{array}$} & $\begin{array}{l}\text { Number of average } \\
\text { education years }(1 / 10)\end{array}$ & $\begin{array}{l}\text { If the average number of years of schooling for a family } \\
\text { member over the age of } 16 \text { is less than } 9 \text { years, it is } 1 \text {; } \\
\text { otherwise, it is } 0 \text {. }\end{array}$ \\
\hline & Dropout rates $(1 / 10)$ & $\begin{array}{l}\text { If the dropout ratio of children aged } 6-16 \text { in a family is } \\
\text { greater than } 0 \text {, it is } 1 \text {; otherwise, it is } 0 .\end{array}$ \\
\hline \multirow{3}{*}{$\begin{array}{l}\text { Health } \\
\text { Condition } \\
(1 / 5)\end{array}$} & Physical health $(1 / 15)$ & If you are not in good health, it is 1 , otherwise it is 0 . \\
\hline & $\begin{array}{l}\text { Chronic diseases } \\
(1 / 15)\end{array}$ & If the individual has a chronic disease, it is 1 , otherwise it is 0. \\
\hline & Mental health $(1 / 15)$ & If the individual is depressed in life, it is 1 , otherwise it is 0. \\
\hline \multirow[t]{3}{*}{$\begin{array}{l}\text { Work } \\
\text { condition }(1 / 5)\end{array}$} & $\begin{array}{l}\text { Long-term unemployed } \\
(1 / 25)\end{array}$ & If long-term unemployed, it is 1 , otherwise it is 0 . \\
\hline & Work formality $(1 / 25)$ & Yes is 1 , otherwise it is 0. \\
\hline & $\begin{array}{l}\text { Job environment } \\
\text { satisfaction }(1 / 25)\end{array}$ & $\begin{array}{l}\text { Job environment satisfaction is rated on a scale of } 1-5 \text {, with } \\
1 \text { if less than } 3 \text { and } 0 \text { if not. }\end{array}$ \\
\hline
\end{tabular}




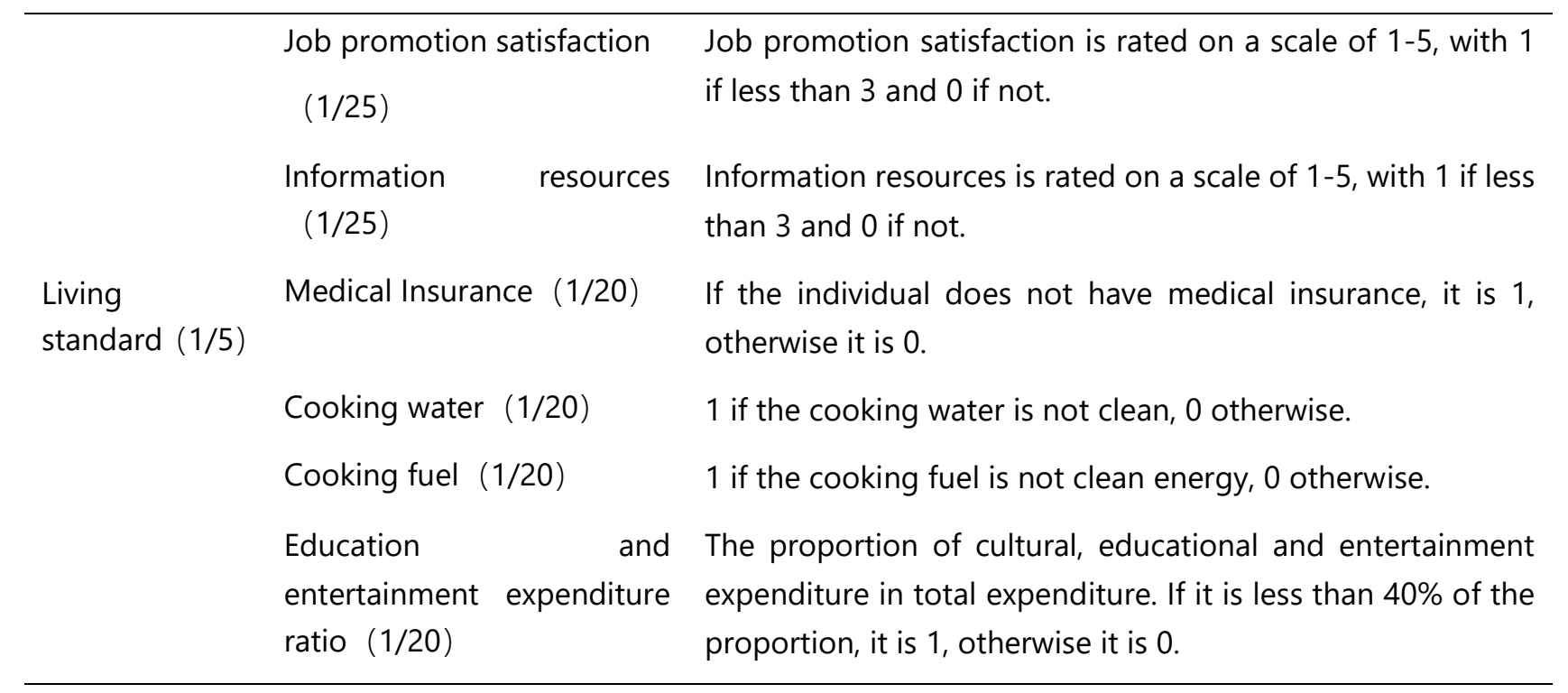

\subsubsection{Multidimensional Poverty Index}

Based on the calculation method of multidimensional poverty index, using the CFPS data from 2010 to 2018, we get the multidimensional poverty index at different critical values. The results are shown in Table 2 . When $k$ is $30 \%$, the multidimensional poverty index is 0.2836 , the incidence of poverty is 0.6385 , and the poverty degree index is 0.4442 , indicating that $63.85 \%$ of individuals are in multidimensional poverty, and the multidimensional poverty degree is 0.4442 .

Table 2 2010-2018 Multidimensional Poverty Index in Ethnic Areas

\begin{tabular}{llll}
\hline $\mathrm{K}$ & $\begin{array}{l}\text { Multidimensional Poverty } \\
\text { index } \\
(\mathrm{M})\end{array}$ & $\begin{array}{l}\text { Multidimensional incidence } \\
\text { poverty }(\mathrm{H})\end{array}$ & $\begin{array}{l}\text { of } \\
\text { Multidimensional poverty degree } \\
\text { index }(\mathrm{A})\end{array}$ \\
\hline $10 \%$ & 0.3652 & 0.9888 & 0.3694 \\
$20 \%$ & 0.3504 & 0.8981 & 0.3902 \\
$30 \%$ & 0.2836 & 0.6385 & 0.4442 \\
$40 \%$ & 0.1892 & 0.3678 & 0.5144 \\
$50 \%$ & 0.1017 & 0.1713 & 0.5939 \\
$60 \%$ & 0.0476 & 0.0717 & 0.6641 \\
\hline
\end{tabular}

\subsection{Variable selection and Model Specification}

\subsubsection{Variable Selection}

\subsubsection{Independent Variables and Dependent Variables}

This part mainly analyzes the influence of Mandarin proficiency on Multidimensional Poverty. The independent variable is the Mandarin proficiency of individuals in ethnic areas. The measurement of Mandarin proficiency comes from the question of "proficiency in Mandarin" in CFPS questionnaire. The measurement of proficiency is expressed by seven grades from 1 to 7 . The higher the grade, the stronger the Mandarin proficiency. The dependent variable is the multidimensional poverty status of individuals in ethnic minority areas. The 
multidimensional poverty index has a direct relationship with the setting of the poverty threshold $\mathrm{K}$, but there is no unified standard for the setting of the $\mathrm{K}$ value. The United Nations Development Programme (UNDP) usually sets $30 \%$ as the poverty threshold, when the poverty score of the sample is more than $30 \%$, it is considered as poor, otherwise it is non multidimensional poverty. Most of China's multidimensional poverty measurement also takes 30\% as the critical value of poverty (Zhang Quanhong, 2015; Gao Ming, 2018; Xiao Rongrong, 2018). Therefore, this paper also takes $30 \%$ as the critical value of multidimensional poverty, calculates the multidimensional poverty index, reflects the multidimensional poverty situation in ethnic areas, and discusses the correlation between Mandarin and multidimensional poverty.

\subsubsection{Control Variables}

The selection of control variables mainly includes three levels, namely, individual level, family level and regional level. Specifically, the control variables at the individual level mainly include the individual's gender, age, marital status, social interaction, social status, non-farm work and other indicators. The main reasons for selecting the above control variables are as follows: gender and marriage will affect the individual's risk tolerance, opportunity and job choice; On the one hand, the increase of age will bring about an increase in working experience, which will have an impact on income. On the other hand, the increase of age will also be accompanied by a decline in physical health, which will affect the income and living standard of individuals. In addition, Zhang W G(2020) pointed out that non-agricultural employment, social status and social interaction were one of the important reasons for Mandarin's influence on economic poverty, health poverty and spiritual poverty. Therefore, the three indicators such as non-agricultural employment, social status and social interaction were taken as individual control variables. The family size was selected as the control variable at the family level, and the dummy variable of the province where the individual lived was added at the region level to control the impact of potential and unobserved regional differences on the regression results.

Table 3 Control Variables

\begin{tabular}{lll}
\hline & Var. & Description \\
\hline & Gender & Male for 1, Female for 0 \\
& Age $2 / 100$ & Age \\
Control & Marriage & Age squared divided by 100 \\
Variables & Social Interaction & On a scale of 1 to 5, the higher the rank, the more social interaction \\
& Family Size & Family size \\
& Social Status & On a scale of 1 to 5, the higher the rank, the higher the status \\
& Non-agriculture Work & Non-agriculture work is 1 , otherwise for 0
\end{tabular}

Note: the data are from CFPS 2010-2018. In the study, the samples were standardized according to the normalization method, that is $y_{i}=\left(x_{i}-\bar{x}\right) / s$.

\subsubsection{Summary Statistics}

Table 4 shows the results of descriptive statistics for all samples. From the perspective of multidimensional poverty, the average of multidimensional poverty in ethnic areas is 0.44 , which indicates that the degree of multidimensional poverty in ethnic areas is in the middle level; from the perspective of language ability, the average of Mandarin proficiency is 2.89 , which is in the middle and lower level of 1 to 7 , which indicates that the 
level of Mandarin in ethnic areas still has a large room for improvement. From the perspective of individual characteristics, the proportion of women in the sample is slightly higher than that of men, the average age is about 44 years old, $61 \%$ of the individual marriage is married, the average family population is about 5 , and the degree of social interaction is 3.78 , indicating that the individual lacks good social interaction, and the average social position is 2.66 , which is in the middle level.

Table 4 Summary Statistics

\begin{tabular}{llllll}
\hline Var. & Size & Mean & Std. Dev & Min & Max \\
\hline Multidimensional Poverty & 8389 & 0.44 & 0.11 & 0.3 & 0.9 \\
Mandarin Proficiency & 8389 & 2.89 & 2.04 & 1 & 7 \\
Gender & 8389 & 0.48 & 0.50 & 0 & 1 \\
Age & 8389 & 43.98 & 17.27 & 18 & 94 \\
Age $^{2} / 100$ & 8389 & 22.3286 & 16.0913 & 1 & 88.36 \\
Marriage & 8389 & 0.61 & 0.49 & 0 & 1 \\
Social Interaction & 8389 & 3.78 & 2.94 & 1 & 10 \\
Family Size & 8389 & 5.32 & 1.93 & 1 & 13 \\
Social Status & 8389 & 2.66 & 1.15 & 1 & 5 \\
Non-agriculture Work & 8389 & 0.77 & 0.42 & 0 & 1 \\
\hline
\end{tabular}

\subsubsection{Model Specification}

In this subsection, we try to analyze the relationship between Mandarin proficiency and multidimensional poverty using the following panel regression model :

$M_{i j t}=\beta_{0}+\beta_{1}$ Language $_{i j t}+\beta_{2}$ controls $_{i j t}+\beta_{3} \operatorname{provcd}_{j t}+\mu_{i j t}$

$M_{i j t}$ represents the Multidimensional Poverty Index, Language $e_{i j t}$ represents the individual's Mandarin proficiency, controls $s_{i j t}$ refers to the control variables of individual, including gender, age, marital status, social interaction, social status, non-agricultural employment, family size, $\operatorname{prov}_{j t}$ represents a locale-level control variable, $\mu_{i j t}$ is a random disturbance term. At the same time, in order to reduce the risk of missing variables caused by the differences in cultural traditions and customs among provinces, this paper also controlled the provincial dummy variables, in addition to controlling the year fixed effect.

\subsection{An Empirical Analysis of Mandarin Proficiency and Multidimensional Poverty}

\subsubsection{Baseline Regression Results}

Table 5 reflects the regression results of Mandarin proficiency to individual Multidimensional Poverty Index. The empirical results show that the improvement of Mandarin proficiency has a significant positive effect on the reduction of individual Multidimensional Poverty in ethnic minority areas. If Mandarin proficiency is improved by one unit, the individual multidimensional poverty index decreases by $7.4 \%$, and it is significant at the level of 1\%. A large number of literatures show that regional economic development level differences and regional differences will have an impact on individual poverty. Therefore, the provincial level dummy variables and time dummy variables are constructed for regression analysis. The results in column (2) are consistent with those in column (1), and the absolute value of the impact rises to $7.56 \%$, which is significant at the level of $1 \%$. 
Furthermore, after controlling for the fixed effects of individual characteristics, family characteristics, provincial level and year, column (3) shows that the improvement of Mandarin proficiency still has a poverty reduction effect on individual Multidimensional Poverty in ethnic minority areas, but its impact has declined. When the Mandarin proficiency changes by one unit, the individual's multidimensional poverty index decreases by $5.49 \%$, and it is significant at the level of $1 \%$.

Table 5 Regression Analysis of Mandarin Proficiency and Multidimensional Poverty

\begin{tabular}{|c|c|c|c|c|}
\hline & OLS & OLS & OLS & $2 S L S$ \\
\hline Var. & Poverty & Poverty & Poverty & Poverty \\
\hline \multirow[t]{2}{*}{ Mandarin } & $-0.0740 * * *$ & $-0.0756^{\star \star *}$ & $-0.0549 * \star \star$ & $-1.278^{* \star *}$ \\
\hline & $(0.0107)$ & $(0.0108)$ & $(0.0110)$ & $(0.283)$ \\
\hline \multirow[t]{2}{*}{ Gender } & & & -0.00572 & $0.145^{\star \star \star}$ \\
\hline & & & $(0.0218)$ & $(0.0476)$ \\
\hline \multirow[t]{2}{*}{ Age } & & & $0.00623^{* *}$ & 0.00380 \\
\hline & & & $(0.00315)$ & $(0.00505)$ \\
\hline \multirow[t]{2}{*}{$\mathrm{Age}^{2} / 100$} & & & $-2.94 e-06$ & $-0.000103^{*}$ \\
\hline & & & $(3.39 e-05)$ & $(5.73 e-05)$ \\
\hline \multirow[t]{2}{*}{ Marriage } & & & 0.0198 & -0.00483 \\
\hline & & & $(0.0231)$ & $(0.0376)$ \\
\hline \multirow[t]{2}{*}{ Social Interaction } & & & 0.00925 & $0.0447^{* * *}$ \\
\hline & & & $(0.00585)$ & $(0.0106)$ \\
\hline \multirow[t]{2}{*}{ Family Size } & & & $-0.0182^{* * *}$ & $-0.0526^{* \star *}$ \\
\hline & & & $(0.00563)$ & $(0.0130)$ \\
\hline \multirow[t]{2}{*}{ Social Status } & & & $-0.0463^{* \star *}$ & 0.0260 \\
\hline & & & $(0.0101)$ & $(0.0246)$ \\
\hline \multirow[t]{2}{*}{ Non-agriculture Work } & & & $-0.121^{\star \star \star}$ & $-0.148^{\star}$ \\
\hline & & & $(0.0290)$ & $(0.0772)$ \\
\hline \multirow[t]{2}{*}{ Constant } & $2.69 e-07$ & 0.0402 & 0.00319 & -0.0749 \\
\hline & $(0.0109)$ & $(0.0319)$ & $(0.0829)$ & $(0.125)$ \\
\hline Observations & 8389 & 8389 & 8389 & 8389 \\
\hline Province fixed effect & $\mathrm{N}$ & $\mathrm{Y}$ & Y & Y \\
\hline Year fixed effect & $N$ & Y & Y & Y \\
\hline
\end{tabular}

Note: Robust standard errors are in parentheses. The ${ }^{*}{ }^{* *}$, and ${ }^{* * *}$ indicate statistics significance at $10 \%, 5 \%$, and $1 \%$ levels. 
Through the above analysis, the improvement of Mandarin proficiency is conducive to reducing the occurrence of individual Multidimensional Poverty, but when the degree of individual poverty is reduced, it may increase the investment of human capital, thus promoting the improvement of Mandarin proficiency. Therefore, there may be reverse causality between Mandarin proficiency and individual multidimensional poverty. At the same time, if the heterogeneity of individuals, families and regions is not observed, it may affect the individual's language ability and poverty level, resulting in biased regression results. To overcome the possible problems of reverse causality and missing variables, this paper uses Zhang W G (2020) ideas and practices, takes the average Mandarin proficiency of other samples from the same region except the interviewees themselves as an instrumental variable, and uses two-stage least square method (2SLS) to reexamine the impact of Mandarin proficiency changes on individual multidimensional poverty. As shown in Table 5, column (4), after adding instrumental variables, the influence of Mandarin proficiency on reducing the degree of multidimensional poverty still exists. This solves the endogeneity problem in the model to some extent and further proves the accuracy of the baseline regression results.

\subsubsection{Robustness Check}

\subsubsection{Mlogit Model}

To ensure the robustness of the regression results, the Multidimensional Poverty Index is classified. Referring to Feng Hexia's (2015) grouping of Multidimensional Poverty and the practice of the United Nations Development Programme (UNDP), the Multidimensional Poverty Index is specifically divided into three categories: $0.3-0.4,0.4$ 0.6 and above 0.6 , corresponding to 1-3 respectively. According to the variable type, mlogit model is selected for regression analysis. The multidimensional poverty level 1 is the ancestor. The regression results are shown in Table 6. Compared with multidimensional poverty level 1, Mandarin proficiency has a significant impact on the reduction of multidimensional poverty. Specifically, for each unit of Mandarin proficiency increase, the log odds of individuals in multidimensional poverty level 2 will decrease by 0.96 , The log odds of individuals in multidimensional poverty level 3 will be reduced by 0.92 , indicating that the improvement of the general level is conducive to reducing the multidimensional poverty in ethnic areas, which is consistent with the regression results in Table 5 of this section, indicating that the regression results are reliable and robust.

Table 6 Robustness Check

\begin{tabular}{lll}
\hline Var. & Multidimensional Poverty Level 2 & Multidimensional Poverty Level 3 \\
\hline Mandarin proficiency & $-0.0343^{* * *}$ & $-0.0877^{* * *}$ \\
& $(0.0120)$ & $(0.0200)$ \\
Gender & $-0.112^{\star *}$ & -0.0573 \\
& $(0.0474)$ & $(0.0756)$ \\
Age & $0.0139^{\star *}$ & 0.00498 \\
& $(0.00699)$ & $(0.0110)$ \\
Age ${ }^{2} / 100$ & $-5.07 \mathrm{e}-05$ & 0.000125 \\
& $(7.53 \mathrm{e}-05)$ & $(0.000114)$ \\
Marriage & -0.0164 & 0.0713 \\
& $(0.0516)$ & $(0.0834)$
\end{tabular}




$\begin{array}{lll}\text { Social Interaction } & -0.00134 & 0.0226 \\ & (0.0131) & (0.0205) \\ \text { Family Size } & -0.00689 & -0.0768^{* * *} \\ & (0.0126) & (0.0204) \\ \text { Social Status } & -0.0865^{* * *} & -0.139^{* * *} \\ & (0.0214) & (0.0340) \\ \text { Non-agriculture Work } & -0.122^{*} & -0.380^{* * *} \\ & (0.0636) & (0.0934) \\ \text { Constant } & 0.123 & -0.530^{*} \\ & (0.191) & (0.306) \\ \text { Observations } & 8389 & 8389 \\ \text { Province fixed effect } & \mathrm{Y} & \mathrm{Y} \\ \text { Year fixed effect } & \mathrm{Y} & \mathrm{Y}\end{array}$

Note: Robust standard errors are in parentheses. The * ${ }^{* *}$, and ${ }^{* * *}$ indicate statistics significance at $10 \%, 5 \%$, and $1 \%$ levels.

\subsubsection{Quantile Regression}

The least square method is used to analyze the impact of Mandarin proficiency on multidimensional poverty in ethnic minority areas, but the estimated result only reflects the impact of Mandarin proficiency on the mean value of conditional distribution of multidimensional poverty. To accurately describe the impact of Mandarin proficiency on the variation range and conditional distribution of multidimensional poverty index, quantile regression method is used to explain the influence of Mandarin proficiency on different multidimensional poverty levels. As shown in Table 7, the general level has a significant negative impact on the multidimensional poverty level of individuals. With the increase of the Multidimensional Poverty Index, the effect of Mandarin proficiency on poverty reduction increases. Specifically, in the $20 \%$ quantile, Mandarin increased by one unit, and the multidimensional poverty index decreased by $2.41 \%$. In the $50 \%$ quantile, the poverty reduction effect of Mandarin was $4.29 \%$, and in the $90 \%$ quantile, the poverty reduction effect of Mandarin was $8.53 \%$, which was significant at the $1 \%$ level. But in the $10 \%$ quantile, Mandarin proficiency has a negative impact on the Multidimensional Poverty Index, but the impact is not significant. 
Table 7 Quantile Regression

\begin{tabular}{|c|c|c|c|c|c|c|c|c|c|}
\hline \multirow[b]{2}{*}{ Var. } & \multicolumn{9}{|c|}{ Dependent variable: Multidimensional Poverty } \\
\hline & $\mathrm{q} 10$ & $\mathrm{q} 20$ & q30 & $\mathrm{q} 40$ & q50 & $q 60$ & q70 & $\mathrm{q} 80$ & q90 \\
\hline \multirow[t]{2}{*}{ Mandarin proficiency } & -0.00852 & $-0.0241^{* \star \star}$ & $-0.0319 * * \star$ & $-0.0435^{\star \star \star}$ & $-0.0429 * * *$ & $-0.0553^{* * *}$ & $-0.0548^{* \star *}$ & $-0.0536^{\star *}$ & $-0.0853^{* * *}$ \\
\hline & $(0.00660)$ & $(0.00889)$ & $(0.0115)$ & $(0.0117)$ & $(0.0150)$ & $(0.0169)$ & $(0.0210)$ & $(0.0230)$ & $(0.0278)$ \\
\hline \multirow[t]{2}{*}{ Gender } & 0.00898 & -0.00652 & -0.0163 & -0.0213 & -0.0381 & 0 & -0.0159 & -0.0242 & 0.0664 \\
\hline & $(0.0129)$ & $(0.0174)$ & $(0.0225)$ & $(0.0227)$ & $(0.0293)$ & $(0.0330)$ & $(0.0409)$ & $(0.0449)$ & $(0.0542)$ \\
\hline \multirow[t]{2}{*}{ Age } & -0.000648 & $5.16 \mathrm{e}-05$ & 0.00451 & 0.00385 & $0.00765^{*}$ & 0.00314 & 0.00570 & 0.00767 & 0.0104 \\
\hline & $(0.00188)$ & $(0.00253)$ & $(0.00328)$ & $(0.00332)$ & $(0.00428)$ & $(0.00482)$ & $(0.00597)$ & $(0.00656)$ & $(0.00792)$ \\
\hline \multirow[t]{2}{*}{$\mathrm{Age}^{2} / 100$} & $2.30 e-05$ & $4.31 \mathrm{e}-05$ & $1.21 \mathrm{e}-05$ & $2.41 \mathrm{e}-05$ & $-9.62 e-07$ & $6.47 e-05$ & $3.90 \mathrm{e}-05$ & $3.27 \mathrm{e}-05$ & $-1.74 \mathrm{e}-05$ \\
\hline & $(2.01 \mathrm{e}-05)$ & $(2.71 \mathrm{e}-05)$ & $(3.50 e-05)$ & $(3.55 \mathrm{e}-05)$ & $(4.57 e-05)$ & $(5.14 \mathrm{e}-05)$ & $(6.38 e-05)$ & $(7.00 \mathrm{e}-05)$ & $(8.45 e-05)$ \\
\hline \multirow[t]{2}{*}{ Marriage } & 0.0101 & 0.0190 & 0.0374 & 0.0133 & 0.00147 & 0.0241 & 0.0414 & $0.0845^{*}$ & 0.0469 \\
\hline & $(0.0135)$ & $(0.0182)$ & $(0.0235)$ & $(0.0238)$ & $(0.0307)$ & $(0.0346)$ & $(0.0428)$ & $(0.0470)$ & $(0.0568)$ \\
\hline \multirow[t]{2}{*}{ Social Interaction } & 0.000989 & -0.00334 & -0.000898 & -0.00122 & 0.00319 & 0.00779 & $0.0150^{* *}$ & $0.0209^{* * *}$ & 0.00995 \\
\hline & $(0.00223)$ & $(0.00301)$ & $(0.00390)$ & $(0.00395)$ & $(0.00509)$ & $(0.00573)$ & $(0.00710)$ & $(0.00780)$ & $(0.00941)$ \\
\hline \multirow[t]{2}{*}{ Family Size } & 0.000297 & $-5.93 e-05$ & -0.00702 & -0.00823 & -0.00778 & -0.00854 & -0.00488 & -0.0184 & $-0.0381^{* * *}$ \\
\hline & $(0.00334)$ & $(0.00451)$ & $(0.00584)$ & $(0.00591)$ & $(0.00762)$ & $(0.00857)$ & $(0.0106)$ & $(0.0117)$ & $(0.0141)$ \\
\hline \multirow[t]{2}{*}{ Social Status } & -0.00677 & $-0.0243^{\star \star \star}$ & $-0.0464^{\star * *}$ & $-0.0459 * * *$ & $-0.0692^{* * *}$ & $-0.0612^{\star * *}$ & $-0.0637^{* * *}$ & $-0.0821^{\star \star \star}$ & $-0.0797^{\star \star \star}$ \\
\hline & $(0.00579)$ & $(0.00781)$ & $(0.0101)$ & $(0.0102)$ & $(0.0132)$ & $(0.0148)$ & $(0.0184)$ & $(0.0202)$ & $(0.0244)$ \\
\hline \multirow[t]{2}{*}{ Non-agriculture Work } & -0.00595 & $-0.110^{* * *}$ & $-0.127^{* * *}$ & $-0.0924^{* * *}$ & $-0.142^{* * \star}$ & $-0.0767^{*}$ & $-0.133^{* * *}$ & $-0.248^{* * *}$ & $-0.256^{\star \star *}$ \\
\hline & $(0.0153)$ & $(0.0206)$ & $(0.0267)$ & $(0.0270)$ & $(0.0348)$ & $(0.0392)$ & $(0.0486)$ & $(0.0533)$ & $(0.0644)$ \\
\hline \multirow[t]{2}{*}{ Constant } & $-1.104^{* * *}$ & $-0.840^{* * *}$ & $-0.651^{* * *}$ & $-0.450^{\star * *}$ & $-0.222^{* *}$ & -0.0216 & $0.279 *$ & $0.828^{\star * *}$ & $1.555^{\star \star \star}$ \\
\hline & $(0.0470)$ & $(0.0633)$ & $(0.0820)$ & $(0.0830)$ & $(0.107)$ & $(0.120)$ & $(0.149)$ & $(0.164)$ & $(0.198)$ \\
\hline Observations & 8389 & 8389 & 8389 & 8389 & 8389 & 8389 & 8389 & 8389 & 8389 \\
\hline
\end{tabular}

Note: Robust standard errors are in parentheses. The *, **, and ${ }^{* * *}$ indicate statistics significance at $10 \%, 5 \%$, and $1 \%$ levels. 


\subsubsection{Heterogeneity Analysis}

\subsubsection{Analysis of Subsamples by Gender and Age}

In order to further study the influence of Mandarin proficiency on the multidimensional poverty index of individuals of different ages and genders, the samples were classified according to gender and age. The genders were divided into two categories: male and female. In the age reference, the labor force was divided into four categories: 18-28 years old, 29-50 years old, 50-65 years old and above 65 years old. The regression results are shown in Table 8. Mandarin proficiency has a significant negative impact on the multidimensional poverty level of individuals, but the influence degree is different for different genders and different age groups. Specifically, on the one hand, from the perspective of the whole sample, the effect of poverty reduction brought by the improvement of male Mandarin proficiency is greater than that of female. When male Mandarin proficiency increases by 1 unit, the multidimensional poverty index decreases by $6.87 \%$, while the multidimensional poverty index of female only decreases by $4.12 \%$, and both of them are significant at the level of $1 \%$. On the other hand, in order to study the poverty reduction effect of Mandarin on different age groups in different genders, on the basis of gender division, the samples are divided into four categories according to age for regression analysis. The results are shown in Table 8(Part B). There are differences in the impact of Mandarin proficiency on the poverty reduction effect of individuals of different age groups. The regression results show that Mandarin proficiency has a significant positive effect on solving multidimensional poverty among 18-28 and 28-50 years old, and it has a great influence on the solution of the poverty of 18-28 years old. 
Table 8 Heterogeneity Analysis(1)

\begin{tabular}{|c|c|c|}
\hline \multirow[b]{3}{*}{ Var. } & \multicolumn{2}{|c|}{ Dependent variable: Multidimensional Poverty } \\
\hline & \multicolumn{2}{|c|}{ Part A } \\
\hline & Male & Female \\
\hline \multirow[t]{2}{*}{ Mandarin proficiency } & $-0.0687^{* * *}$ & $-0.0412^{* * *}$ \\
\hline & $(0.0154)$ & $(0.0157)$ \\
\hline \multirow[t]{2}{*}{ Age } & $0.0110^{* *}$ & 0.00189 \\
\hline & $(0.00454)$ & $(0.00438)$ \\
\hline \multirow[t]{2}{*}{$\mathrm{Age}^{2} / 100$} & $-2.96 e-05$ & $2.30 \mathrm{e}-05$ \\
\hline & $(4.94 \mathrm{e}-05)$ & $(4.65 e-05)$ \\
\hline \multirow[t]{2}{*}{ Marriage } & $0.0596^{*}$ & -0.0312 \\
\hline & $(0.0325)$ & $(0.0328)$ \\
\hline \multirow[t]{2}{*}{ Social Interaction } & $0.0163^{* *}$ & 0.00382 \\
\hline & $(0.00787)$ & $(0.00869)$ \\
\hline \multirow[t]{2}{*}{ Family Size } & -0.00746 & $-0.0315^{\star * *}$ \\
\hline & $(0.00825)$ & $(0.00762)$ \\
\hline \multirow[t]{2}{*}{ Social Status } & $-0.0707^{* * *}$ & $-0.0239^{*}$ \\
\hline & $(0.0144)$ & $(0.0142)$ \\
\hline \multirow[t]{2}{*}{ Non-agriculture Work } & -0.0570 & $-0.177^{* * *}$ \\
\hline & $(0.0424)$ & $(0.0397)$ \\
\hline \multirow[t]{2}{*}{ Constant } & -0.136 & 0.162 \\
\hline & $(0.118)$ & $(0.114)$ \\
\hline Province fixed effect & Y & $\mathrm{Y}$ \\
\hline Year fixed effect & $Y$ & $Y$ \\
\hline
\end{tabular}




\begin{tabular}{|c|c|c|c|c|c|c|c|c|}
\hline & \multicolumn{2}{|c|}{ Part B } & \multicolumn{4}{|c|}{ 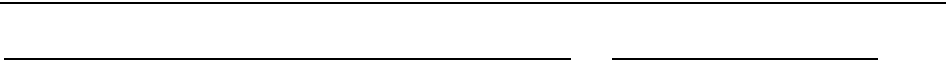 } & \multicolumn{2}{|c|}{ 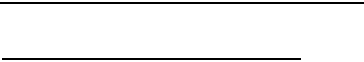 } \\
\hline & \multicolumn{2}{|c|}{ A. Age 18-28 } & \multicolumn{2}{|c|}{ B. Age $29-50$} & \multicolumn{2}{|c|}{ C. Age51-65 } & \multicolumn{2}{|c|}{ D. 65 岁以上 } \\
\hline & Male & Female & Male & Female & Male & Female & Male & Female \\
\hline \multirow[t]{2}{*}{ Mandarin proficiency } & $-0.101^{* \star *}$ & $-0.0604^{*}$ & $-0.0604^{\star \star \star}$ & $-0.0191^{*}$ & -0.0446 & -0.0254 & -0.0272 & -0.0510 \\
\hline & $(0.0325)$ & $(0.0318)$ & $(0.0225)$ & $(0.0334)$ & $(0.0348)$ & $(0.0372)$ & $(0.0543)$ & $(0.0529)$ \\
\hline \multirow[t]{2}{*}{ Marriage } & 0.0507 & -0.0453 & 0.0816 & 0.0242 & -0.0155 & -0.0469 & $0.161^{*}$ & -0.0664 \\
\hline & $(0.0666)$ & $(0.0674)$ & $(0.0509)$ & $(0.0578)$ & $(0.0758)$ & $(0.0659)$ & $(0.0928)$ & $(0.0817)$ \\
\hline \multirow[t]{2}{*}{ Social Interaction } & $-0.0336^{* \star *}$ & -0.000928 & $0.0316^{* *}$ & -0.00993 & $0.0369^{\star *}$ & 0.00800 & 0.0106 & -0.0127 \\
\hline & $(0.0127)$ & $(0.0170)$ & $(0.0135)$ & $(0.0153)$ & $(0.0185)$ & $(0.0182)$ & $(0.0219)$ & $(0.0248)$ \\
\hline \multirow[t]{2}{*}{ Family Size } & -0.00283 & $-0.0463^{* * *}$ & 0.00904 & -0.00113 & 0.00636 & $-0.0362^{* *}$ & $-0.131^{* * *}$ & $-0.121^{\star * *}$ \\
\hline & $(0.0165)$ & $(0.0172)$ & $(0.0124)$ & $(0.0122)$ & $(0.0165)$ & $(0.0152)$ & $(0.0228)$ & $(0.0210)$ \\
\hline \multirow[t]{2}{*}{ Social Status } & 0.0439 & 0.0380 & $-0.0890^{* \star *}$ & $-0.0819^{* * *}$ & $-0.113^{\star * *}$ & 0.0102 & -0.00336 & 0.0383 \\
\hline & $(0.0327)$ & $(0.0331)$ & $(0.0212)$ & $(0.0225)$ & $(0.0314)$ & $(0.0299)$ & $(0.0373)$ & $(0.0339)$ \\
\hline \multirow[t]{2}{*}{ Non-agriculture Work } & $-0.162^{*}$ & $0.181^{* *}$ & -0.0143 & $-0.204^{\star \star \star}$ & -0.0782 & $-0.367^{* * *}$ & 0.0319 & $-0.263^{\star *}$ \\
\hline & $(0.0888)$ & $(0.0755)$ & $(0.0586)$ & $(0.0598)$ & $(0.114)$ & $(0.100)$ & (0.109) & $(0.103)$ \\
\hline \multirow[t]{2}{*}{ Constant } & $-0.449^{* \star *}$ & -0.264 & -0.0214 & $0.302^{* *}$ & $0.705^{\star \star \star}$ & $0.466^{* *}$ & $1.375^{\star \star \star}$ & $1.032^{\star * *}$ \\
\hline & $(0.151)$ & $(0.164)$ & $(0.128)$ & $(0.134)$ & $(0.216)$ & $(0.193)$ & $(0.211)$ & $(0.195)$ \\
\hline Province fixed effect & $\mathrm{Y}$ & Y & $\mathrm{Y}$ & $Y$ & $\mathrm{Y}$ & Y & Y & $Y$ \\
\hline Year fixed effect & Y & Y & Y & Y & Y & Y & Y & Y \\
\hline
\end{tabular}

Note: Robust standard errors are in parentheses. The ${ }^{*},{ }^{* *}$, and ${ }^{* * *}$ indicate statistics significance at $10 \%, 5 \%$, and $1 \%$ levels. 


\subsubsection{Analysis of Subsamples by Employment}

As one of the seven key poverty alleviation measures, a large number of literature proves that the transfer of workers' employment across departments is beneficial to the increase of income level and plays a positive role in solving poverty. Therefore, this part analyzes the influence of Mandarin proficiency on multidimensional poverty of agricultural and non-agricultural employment. The empirical results are shown in Table 9. The regression results show that the improvement of Mandarin proficiency has a significant positive impact on solving the multidimensional poverty of agricultural and non-agricultural employment, among which, it has a great impact on solving the multidimensional poverty of non-agricultural employment, when Mandarin changes a unit, the multidimensional poverty of agricultural workers decreased by $3.68 \%$, but the multidimensional poverty of non-agricultural workers decreased by $10.1 \%$, and all of them were significantly at the level of $1 \%$. It is also in line with the reality. Mandarin, as a tool of human capital and communication, has a significant positive impact on the improvement of the income level of workers, and also has a positive impact on the integration of non-agricultural workers into local life, thus affecting their education, health, living standards and working conditions, and thus reducing the level of multidimensional poverty.

Table 9 Heterogeneity Analysis(2)

\begin{tabular}{|c|c|c|}
\hline \multirow[b]{2}{*}{ Var. } & \multicolumn{2}{|c|}{ Dependent variable: Multidimensional Poverty } \\
\hline & Agricultural Work & Non-agricultural Work \\
\hline \multirow[t]{2}{*}{ Mandarin proficiency } & $-0.0368^{* * \star}$ & $-0.101^{* * *}$ \\
\hline & $(0.0121)$ & $(0.0248)$ \\
\hline \multirow[t]{2}{*}{ Gender } & 0.00258 & -0.0303 \\
\hline & $(0.0242)$ & $(0.0482)$ \\
\hline \multirow[t]{2}{*}{ Age } & 0.00500 & $0.0126^{*}$ \\
\hline & $(0.00352)$ & $(0.00710)$ \\
\hline \multirow[t]{2}{*}{$\mathrm{Age}^{2} / 100$} & $-1.13 e-05$ & $-2.06 e-05$ \\
\hline & $(3.81 e-05)$ & $(7.50 \mathrm{e}-05)$ \\
\hline \multirow[t]{2}{*}{ Marriage } & 0.0110 & $0.0939^{*}$ \\
\hline & $(0.0255)$ & $(0.0518)$ \\
\hline \multirow[t]{2}{*}{ Social Interaction } & $0.0194^{\star * *}$ & $-0.0475^{\star \star \star}$ \\
\hline & $(0.00635)$ & $(0.0135)$ \\
\hline \multirow[t]{2}{*}{ Family Size } & $-0.0183^{* \star *}$ & $-0.0426^{\star \star \star}$ \\
\hline & $(0.00654)$ & $(0.0120)$ \\
\hline \multirow[t]{2}{*}{ Social Status } & $-0.0445^{\star \star *}$ & $-0.0708^{* \star *}$ \\
\hline & $(0.0111)$ & $(0.0229)$ \\
\hline \multirow[t]{2}{*}{ Constant } & $-0.221^{* *}$ & 0.135 \\
\hline & $(0.0970)$ & $(0.167)$ \\
\hline
\end{tabular}




$\begin{array}{lll}\text { Province fixed effect } & Y & Y \\ \text { Year fixed effect } & Y & Y \\ \text { Observations } & 6429 & 1960\end{array}$

Note: Robust standard errors are in parentheses. The ${ }^{*}{ }^{* *}$, and ${ }^{* * *}$ indicate statistics significance at $10 \%, 5 \%$, and $1 \%$ levels.

\section{Conclusion}

To study the correlation between Mandarin proficiency and multidimensional poverty, we use the CFPS data from 2010 to 2018. Firstly, we select 15 indicators from five aspects of economy, education, health, living standards and work conditions to construct Multidimensional Poverty Indicators and calculate the degree of Multidimensional Poverty in ethnic areas. Secondly, based on the Multidimensional Poverty Index, we analyze the relationship between language and multidimensional poverty The research shows that the improvement of Mandarin proficiency has a significant positive effect on the reduction of individual Multidimensional Poverty in ethnic areas. If Mandarin proficiency is improved by one unit, the individual multidimensional poverty index decreases by $7.4 \%$, and it is significant at the level of $1 \%$. To solve the problem of endogeneity and ensure the robustness of the regression results, endogeneity analysis and robustness test were carried out respectively, and the results were consistent with the regression results, which showed that the regression results were robust and reliable. Finally, in order to analyze the impact of Mandarin proficiency on different sample individuals, we conducted the quantile regression and heterogeneity analysis. The results show that with the increase of the multidimensional poverty index, the effect of Mandarin proficiency on poverty reduction increases. The effect of Mandarin proficiency of men is greater than that of women. It has a positive impact on the reduction of multidimensional poverty of workers aged $18-28$ and $28-50$, and has a greater impact on the reduction of multidimensional poverty of non-agricultural employment.

\section{References}

1. Alisher Aldashev, Johannes Gernandt, Stephan L. Thomsen.(2009). Language usage, participation, employment and earnings: evidence for foreigners in west Germany with multiple sources of selection. Labor Economics, Vol.16, p.330 341.

2. Antonio Di Paolo, Aysit Tansel. (2015). Returns to foreign language skills in a developing country: the case of Turkey. The Journal of Development Studies, Vol.51, p.407 421.

3. Barry R. Chiswick, Harry Anthony Patrinos, Michael E.Hurst. (2000). Indigenous language skills and the labor market in a developing economy: Bolivia. Economic Development and Culture Change.Vol.48,p.349 367.

4. Bian Chenglin, Liu Jinlin, Yang Liuyan.( 2019).A study on the relationship between language ability and economic income of border residents in China and Vietnam: a case study of Dongxing City in Guangxi. Chinese Journal of Language Policy and Planning, Vol.4,p.56-66.

5. Chen Yuanyuan.( 2016). The influence of Mandarin proficiency on the income of Chinese workers . Economic Review, Vol.06,p.108-122.

6. Christian Dustmann, Francesca Fabbri. (2003). Language proficiency and labor market performance of immigrants in the UK. The Economic Journal, Vol.113, p.695-717.

7. Daniela Casale, Dorrit Posel. (2011). English language proficiency and earnings in a developing country: the case of South Africa. The Journal of Socio-Ecnomics, vol.40 ,p.385-39.

8. Evelina Tainer.(1988).English language proficiency and the determination of earnings among foreign- 
born men[J].The Journal of Human Resources, Vol.23, p.108 122 .

9. Geoffrey Carliner. (1981).Wage differences by language group and the market for language skills in Canada. The Journal of Human Resources, Vol.16, p.384 399.

10. Jiang Shan.(2017).Research on the influence of social capital on the citizenization of migrant workers . Beijing Forestry University.

11. Jacob Marschak.(1965). Economics of language. Behavioral Science, Vol.10,p.135-140.

12. Jin Jiang, Yin Feifei, Lian Jie.(2017).Empirical test on the relationship between Mandarin proficiency and employment. Research on Institutional Economics, Vol.01,p.202-218.

13. Mehtabul Azam, Aimee Chin ,Nishith Prakash.(2013).The returns to English-language skills in India. Economic Development and Culture Change, Vol.61,p.335 367.

14. Sen, Amartya.(1999). Development as Freedom. Oxford University Press .

15. Tang Manping, Li Houjian.( 2019).Research on the poverty reduction effect of Mandarin skills for farmers -- Based on the economic and social survey of Western Ethnic Regions. China Economic Studies, Vol.02,p.122-136.

16. Walter McManus, William Gould, Finis Welch.(1983).Earnings of Hispanic Men: the role of English language proficiency. Journal of Labor Economics, Vol.1, p.101-130.

17. Wang Hailan, Cui Meng, NIMA Ciren.( 2019). A study on the income effect of Mandarin proficiency in "three regions and three prefectures" - a case study of Bomi County in Tibet Autonomous Region. Journal of Yunnan Normal University(Humanities and Social Sciences), Vo.5,p.49-58.

18. Xia Li.(2009). Language resources and language problems of urban migrant workers. Journal of Yunnan Normal University(Humanities and Social Sciences), Vol.41,p.8-14.

19. Xie Zhiju, Li Qiang.(2020). Language poverty alleviation and the poverty alleviation effect of Mandarin skills. Journal of Guangxi University for Nationalities(Philosophy and Social Science Edition),Vol.42.p.167174.

20. Zhang Quanhong, Zhou Qiang. (2015). Multidimensional method and empirical application of poverty measurement in China. China Soft Science, Vol.07,p.29-41.

21. Zhang W G. (2020).The effect of Mandarin proficiency on poverty reduction: An empirical analysis based on economic, health and spiritual dimensions. Applied Linguistics, Vol.04,p.37-51.

22. Zhao Ying.(2016).Measurement and analysis of the contribution of language ability to workers' income . Economics Information, Vol.01,p.32-43. 